\title{
Pros and Cons: Web Based Education
}

\author{
Liu Jingyu \\ Foreign Language Department \\ Jiangxi Yuzhou Vocational College of Science and Technology \\ Xinyu City, China \\ Liujingyu210@163.com
}

\begin{abstract}
The world of web-based education is changing more quickly. Online education offers students an anytime/anywhere method of receiving an advanced knowledge. Proponents point out the increased access will level the playing field for all. Online course enrollment may be on the rise; however, with growth may have come growing pains.This study explores the benefits and issues of the web-based education for the students and professors.
\end{abstract}

Keywords-online education; students and professors; pros and cons

\section{INTRODUCTION}

Web-based education, also known as online learning, or online education, is quickly changing the face of higher education because it attracts students of all ages (Truluck, 2007).

Berge (2000) and his colleagues assert, "For maximum effectiveness, training and learning opportunities must go to the students and arrive just-in-time. For these and other reasons, demographics and competition no longer allow instructors or trainers to insist on 'my place at my pace.' Totally online Web-based courses offer benefits for learners and trainers/instructors alike” (p. 35).

Though there are many advantages to offering web based education, web based education is not without its challenges. Many of the challenges are directly related to the same advantages of web-based education (Cook, 2007). This study explores the benefits and issues for those tasked with those who are teaching the students and the students themselves. This study focuses on the higher education faculty and students who enroll in online courses. The pros of online education will be balanced with the possible cons of Internet education versus face-to-face education.

\section{PROS AND CONS : WEB-BASED EDUCATION FOR STUDENTS}

\section{A. Flexibility vs. Time Management in Online Classes}

Taking online classes at home or other places of their choosing allows students maximum control over their time. Online classes offer convenient, 24-hour access to courses and do not depend on the proximity to the organization or school offering the course. Online course environments may have classes more frequently than are offered through a traditional on-campus program.

- Pros: One of the main advantages of the flexibility of online learning is accommodating work and other responsibilities. Web based education allows students to take control of their own learning and therefore learn at their own pace. Students can be given greater control over the learning environment by allowing them to select from the learning modules or course material which best assists their own understanding and retention. In addition, material can be reviewed at a later time or as many times as necessary in order to master specific skills or retain knowledge According to Indiana University, most students work full time while taking classes (www.indiana.edu). Working students in a study conducted by the University of Wisconsin on student's satisfaction with distance learning courses found flexibility to be the key benefit of online learning (www.uwex.edu). According to the study, part-time students who worked full-time evaluated online courses more positively than full-time students. Besides, Online education allows instructors to reach students in different geographical areas as well as students who would otherwise be unreachable. Students such as working adults, stay at home moms, the military deployed, and the elderly and handicapped now have unlimited opportunities to take courses and attain degrees from a distance because they are no longer limited to educational opportunities which are within driving distance of their home. This in and of itself has far-reaching implications in that it helps students obtain an education.

- Cons: According to a study published in the Journal of Information Technology Education students perceive time management as a major disadvantage to controlling their own coursework. Some students reported that online courses requires too much or more self motivation, organization and planning than coursework at a traditional university, particularly in required work for the course. In discussing the benefits and challenges of taking its courses online vs. traditional, the University of Connecticut warns students to plan their flexible time wisely when completing course assignments to avoid procrastination (www.uconn.edu).

\section{B Technology vs. Student Engagement in Online Classes}

Online courses rely on Internet technology trends. Students do not interact face-to-face with each other or with the instructor, but use web pages, e-mail, software programs such as Blackboard or WebCT, message boards, 
chat rooms, webinars, webcasts and social media. Work assignments most often are written and rely on Internet research rather than primary source library research.

- Pros: Advantages to online students in terms of technology depend on the preferred learning style of the student. Students who prefer online classes may find that online learning fits their learning style, giving them more time to think about answering questions and allowing them the option interact with classmates with whom they might not connect with socially. A study conducted by researchers at Valdosta State University (www. teach.valdosta.edu) found that students who favored online learning tended to be independent learners, while a study published in the Journal of College Teaching and Learning found online students to be slightly more introverted.

- Cons: Disadvantages of technology in online classes can include concerns about technical problems and limitations of one kind of instructional delivery, demonstrating learning and turning in assignments. The success of web based education is very dependent upon the technology. When the technology fails, the online course can fail with it. This causes student frustration and dissatisfaction, particularly to students who are already uncomfortable or unfamiliar with the technology or the online environment in general. This causes the students to either avoid the course or focus on the technology rather than the content. Cook (2007) asserts, "Even minor problems can be a serious impediment, decreasing satisfaction and course participation while increasing cognitive load, which in turn impede learning”. A Harvard University study found that for all the promises of technology, bored students drop out (www.harvard.edu). Researchers at Clemson University and Lander University, writing for The Journal of Educators Online, studied dropout rates in online courses and found that student engagement, particularly socially, was a key factor in retaining students in online courses. A study published in the Online Journal of Distance Learning Administration reported that students felt that not all course content or subjects translate well into an online environment, particularly those that may require feedback from the instructor in handson, real time learning.

In conclusion, no matter the environment, education requires a firm commitment of time, money and other resources. Students who need the personal interaction with peers presented by in-class face time might need to think twice about completing the majority of their education online. Yet, one who loves control over time and resources might feel right at home in an online class.

\section{PROS AND CONS: WEB-BASED EDUCATION FOR PROFESSORS}

A major benefit of online education for professors is that an online environment is time-independent and placeindependent. Online education provides convenience and flexibility for professors. The less demanding work environment enables professors to attend conferences, present papers, recruit for the university. Professors who teach online courses can be compared to those who telecommute. According to study by Brigham Young University (2010) 25 percent of employees reported that work interfered with personal and family life. A member of the faculty at Brigham Young University also concluded that flexible work options is connected to increased production, more flexibility in the workplace and reduced office space needs. That's the good side. Online education decreases limitations and increases diversity among the student population. The wide range of students' geographies, cultures, backgrounds, and ages bring new ideas and premonitions of the subjects being introduced in the course. Students in the course are able to gain a much broader prospective on the subjects at hand which make for a richer learning environment .

However, for the professor tasked with developing and conducting an online class, a significant portion of their time will be required. Although web based education offers the instructors flexibility and the convenience to determining their teaching schedule, the time demands are greater for teaching a course in the online format than for teaching a course in a face-to-face setting (Cavanaugh, 2005). Cavanaugh conducted a study that did a time comparison between a course taught online and a course taught in the face-to-face setting (same class and same instructor). He contends, "The amount of time spent teaching online was over twice the amount of time spent teaching in-class". Cavanaugh further states that the amount of time spent teaching an online course seems to increase directly with the number of students enrolled and that the major difference in the additional time spent is largely due to communication with the student (time emailing, time spent answering students' questions). The American Association of University Professors found that online courses take more time to conduct than traditional courses. Online professors find a huge amount of time spent in answering individual questions which could be handled class-wide in a face-to-face environment. Additionally learning multiple course management system software packages requires a learning curve use of time. Discussions with students can take place $24 / 7$ and students expect immediate feedback online.

Online education opens up a Pandora's Box for professors. Many of the evils from this box are substance from the lack of physical interaction between the student and teacher. Dykman and Davis articulated the value of the physical human interaction as it relates to education, "Without significant human contact, students may seek to get by with the least amount of effort possible, and their learning and the quality of the online course will suffer 
accordingly"(p.288).

Many professors are concerned with the increased risk of academic dishonesty. Students who want to cheat will find a way; however, research has found that it is easier for students to cheat in online classes. Although the course management system, eCollege, continues to implement changes to their software package to make the assessment portion more secure robust, students can easily use a simple screenshot of their monitor to save and share test questions. Therefore, professors must rethink how they choose to assess their students in order to increase the true validity of the exam results. On response from an SHSU like/dislike survey of online classes pointed out that this can be accomplished as the student said, "You had to study beforehand. You didn't have time to look up the answers." This was definitely in the dislike section! Another issue for professors is the constant demand of written communication. E-mail is a great way to communicate technical messages, but is not a great way to communicate emotional messages. In a traditional classroom, professors can read body language, pick out sarcasm, and reflect on tone while a student expresses their issues, confusion, or excitement. E-mail is written word that can be stored and forwarded; it has the possibility to haunt the professors and affect a teacher's position, tenure or reputation.

Professors must also be more aware of students in online courses who are not self-regulated. Self-regulated learners set goals and monitor and react with regards to their progress towards their goals. Professors can add encouragement, deadlines, and scheduling reminders to the Internet class documents. They can communicate to the students the importance of doing the assigned reading, meeting deadlines, and taking exams, but if the student is not disciplined and motivated enough to check-in to the online course or read their e-mail, then the teacher is forced to fail the student. For instance at one institution of higher learning (Sam Houston State University), they have a special advising Center called Sam Center which provides a "First Alert" process whereby they will follow up with students and try to get them on track or drop the class.

Professors have the issues surrounding self-regulated excuse makers. These students tend to monitor the course but fail to produce results. These students constantly have a crisis, a schedule conflict, a family emergency, or some other justification for not doing the coursework. Professors have to wade through the written communication and make determination if the student is worthy of an extension. Not only is this possibly unfair to other students, it can be technologically challenging to alter course management system deadlines without intervention from others.

Some research shows that students in online courses perform worse than those in traditional classrooms. Students that have low technological, communication, or organizational skills and professors need to be ready to approach these issues in order to help the student succeed.

\section{SUMMARY}

Online education continues to gain popularity as the demands for an educated workforce continue to increase. Students who work full-time, have children at home, have odd work hours, or live across the globe can attend class in the comfort of their homes. Students with handicaps can take classes without special arrangements for travel or in the classroom. With enhanced access in the form of online education, student enrollment will increase. Ease of access, convenience, and flexibility is not only beneficial for the student population; it also is attractive to faculty. The flexible work schedule and environment makes it easy for universities to obtain the best faculty and more faculties to meet the demands of increased enrollment.

The main benefit of online education is both faculty and students is that it allows time and place independent access. The issues of online education tend to vary significantly between institutions, professors, students, and employers. Professors and students have issues with student self-regulation and written communication, with more emphasis. Online education has long had its proponents and naysayers. Do the benefits of online education outweigh the issues? The answer: It depends .

Finally, the student survey on their perspectives of technology use in their courses indicates several benefits-from better understanding to better communication with their instructors. It is clear that students perceive some positives of technology use in this setting.

\section{REFERENCES}

[1] Atkinson , cited in Valentine 2002 \& NG, 2000)

[2] Carr, S. (2000, February 11). As distance education comes of age, the challenge is keeping the students [Electronic version]. Chronicle of Higher Education, A39.

[3] Cook, D. A. (2007). Web-based learning: pros, cons and controversies. Clinical Medicine, 7 (1), 37-42.

[4] Kern, R. (2010). Maximizing an Online Education. U.S. News \& World Report, 147(5), 46-47. Retrieved from Business Source Complete database.

[5] Li, C., \& Irby, B. (2008). An Overview of Online Education: Attractiveness,Benefits, Challenges, Concerns and Recommendations, College Student Journal, 42(2), 449-458. Retrieved from Academic Search Complete database.

[6] McNair, P., Thompson, T. (2007). Creating a first class experience that's first class. Online Journal of Distance Learning Administration, 10(3). Retrieved April 3, 2008, from http://www.westga.edu/ distance/ojdla/fall103/mcnair103.htm.

[7] Millson, M., \& Wilemon, D. (2008). Technology Enabling Innovation in Online Graduate Management Education. International Journal of Innovation \& Technology Management, 5(4), 401-421.

[8] Trawick, M., Lile, S., \& Howsen, R. (2010). Predicting Performance for Online Students: Is It Better to be Home Alone?. Journal of Applied Economics \& Policy, 29(1), 34-46. 